Supplement of Saf. Nucl. Waste Disposal, 1, 161-162, 2021

https://doi.org/10.5194/sand-1-161-2021-supplement

(C) Author(s) 2021. CC BY 4.0 License.

(c) (i)

Supplement of

\title{
Geochemical benchmark tests to validate the conversion of thermodynamic data for TOUGHREACT
}

Torben Weyand et al.

Correspondence to: Torben Weyand (torben.weyand@bfe.bund.de)

The copyright of individual parts of the supplement might differ from the article licence. 


\section{Geochemical benchmark tests to validate the conversion of thermodynamic data for TOUGHREACT}

\section{Introduction}

- The reactive transport of radionuclides in long term safety analyses for nuclear waste disposal sites can be modelled using the geochemical code TOUGHREACT [1].

- Most host rocks under consideration in the ongoing site selection process in Germany have pore waters with high ionic strengths. Therefore, specific thermodynamic data using the Pitzer approach [2] needs to be applied in TOUGHREACT.

- As a consequence, a tool is necessary to convert the thermodynamic data using the Pitzer approach for usage in TOUGHREACT and the tool needs to be validated.

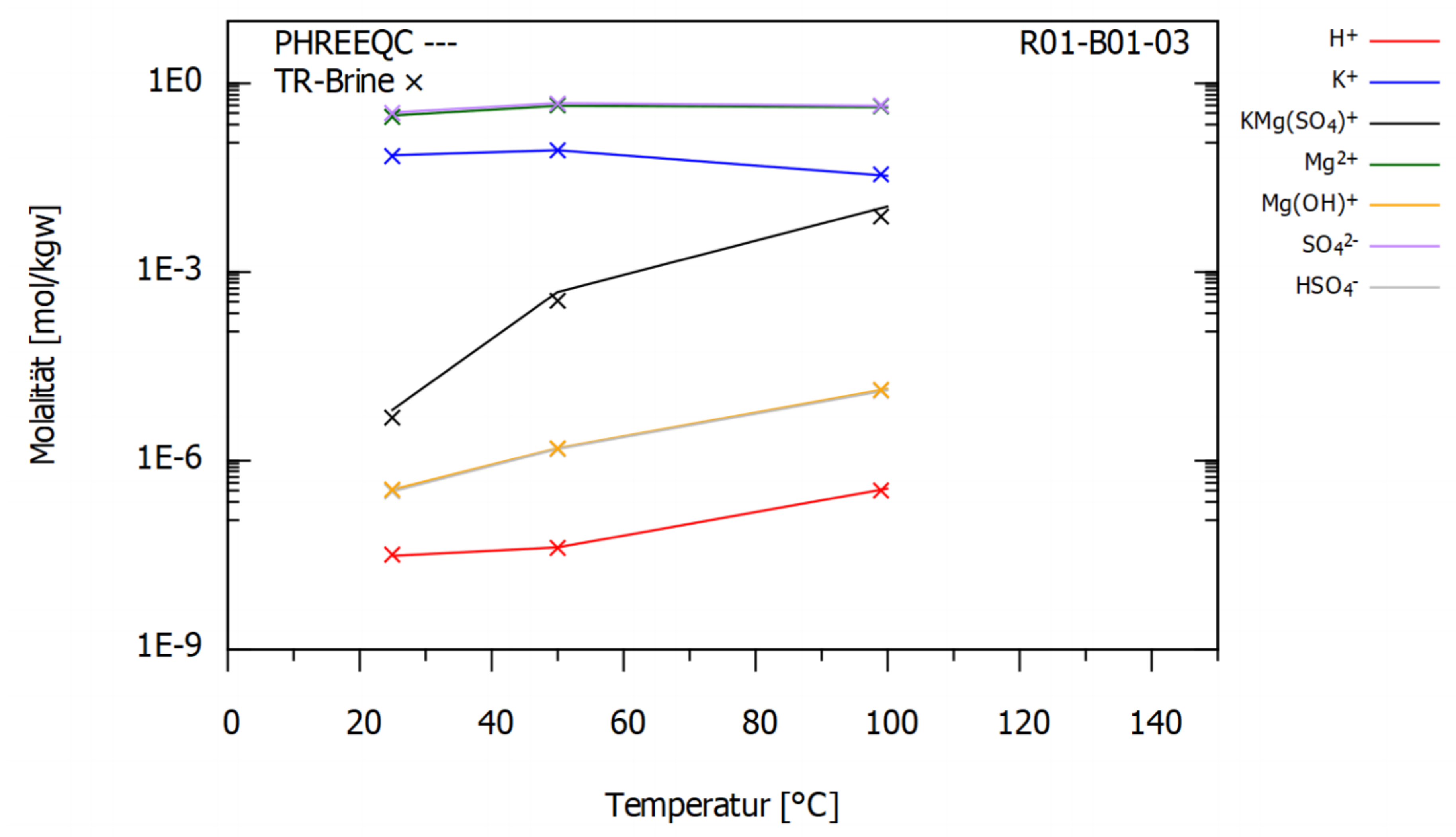

Fig. 1 Molality of aquatic species versus temperature for the system K-Mg-SO4 (equilibrium with epsomite and picromerite) calculated by PHREEQC (lines) and TOUGHREACT (crosses)

\section{Results}

- With each calculation the specific aquatic speciation were derived by PHREEQC \& TOUGHREACT. The results of both codes were compared between each other.

- The results of the calculations of both codes agree well for three geochemical systems:

o oceanic salt system, polythermal: $\mathrm{K}, \mathrm{Mg}, \mathrm{Ca}-\mathrm{Cl}$, $\mathrm{SO}_{4}-\mathrm{H}_{2} \mathrm{O}(\mathrm{l})$ (e.g. Fig. 1)

$\circ$ actinide system, isothermal: Am(III), $\mathrm{Cm}$ (III), $\mathrm{Nd}$ (III) - $\mathrm{Na}, \mathrm{Mg}, \mathrm{Ca}-\mathrm{Cl}, \mathrm{OH}-\mathrm{H}_{2} \mathrm{O}$ (l) (e.g. Fig. 2)

- carbonate system, isothermal: $\mathrm{Na}, \mathrm{K}, \mathrm{Mg}, \mathrm{Ca}-\mathrm{Cl}$, $\mathrm{SO}_{4}-\mathrm{HCO}_{3} / \mathrm{CO}_{2}$ (g) - $\mathrm{H}_{2} \mathrm{O}$ (l) (e.g. Fig. 3)

- Minor deviations are explainable by technical differences of the codes [4].

\section{Description of the work}

$\circ \quad$ The THEREDA project [3] provides thermodynamic data using the Pitzer approach for some widely used geochemical codes (e. g. PHREEQC). Scripts were developed to convert thermodynamic data of the THEREDA project to be applicable in TOUGHREACT.

- The validation of the scripts is performed by comparing results of 50 different calculations (speciation / concentrations at geochemical equilibria) using PHREEQC and TOUGHREACT for three geochemical systems [4], which are relevant for long term safety analyses.

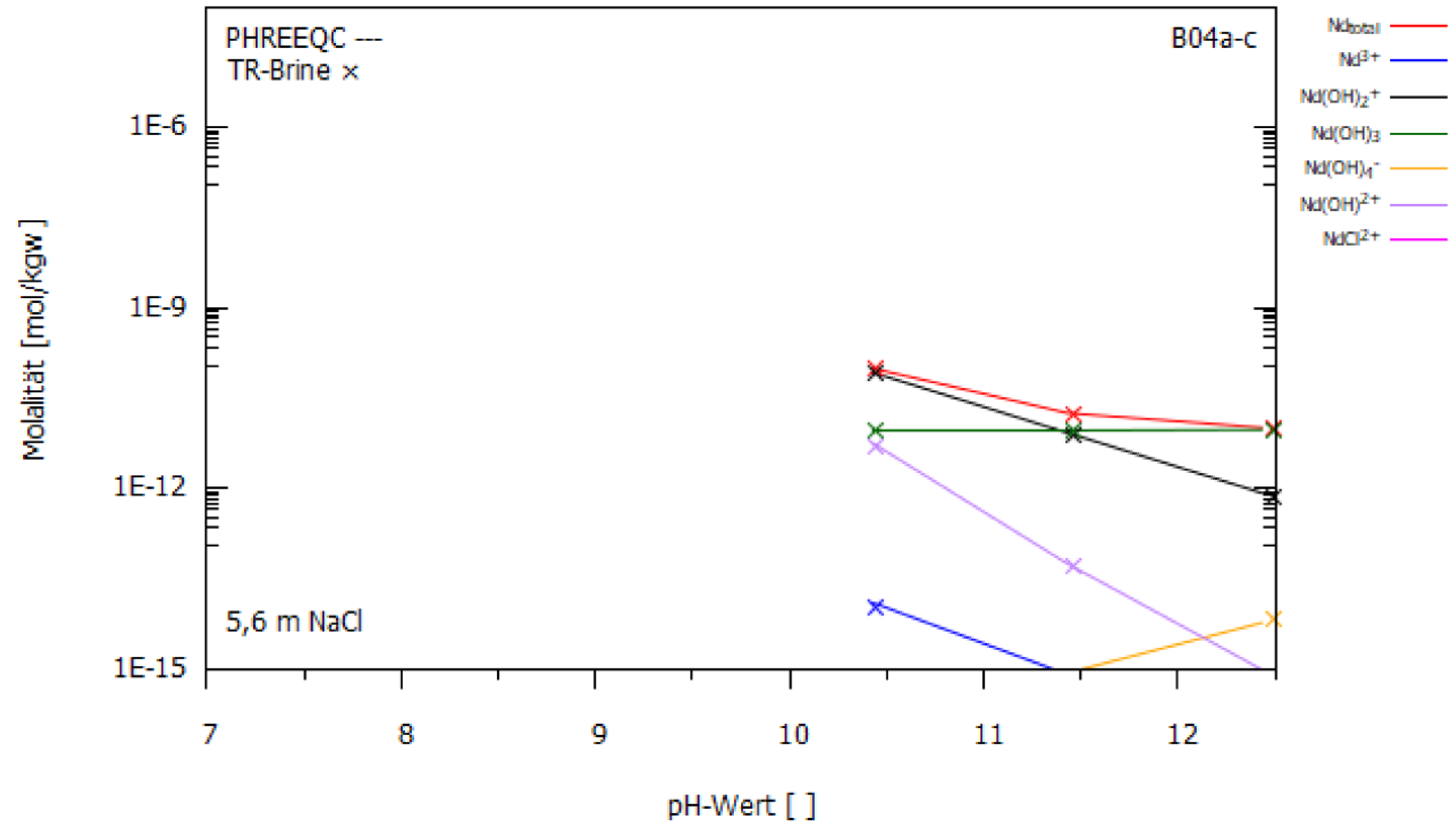

Fig. 2 Molality of aquatic species versus $\mathrm{pH}$ for a 5,6 $\mathrm{m} \mathrm{NaCl}-$ solution in equilibrium with $\mathrm{Nd}(\mathrm{OH})_{3}(\mathrm{am})$ calculated by PHREEQC (lines) and TOUGHREACT (crosses)

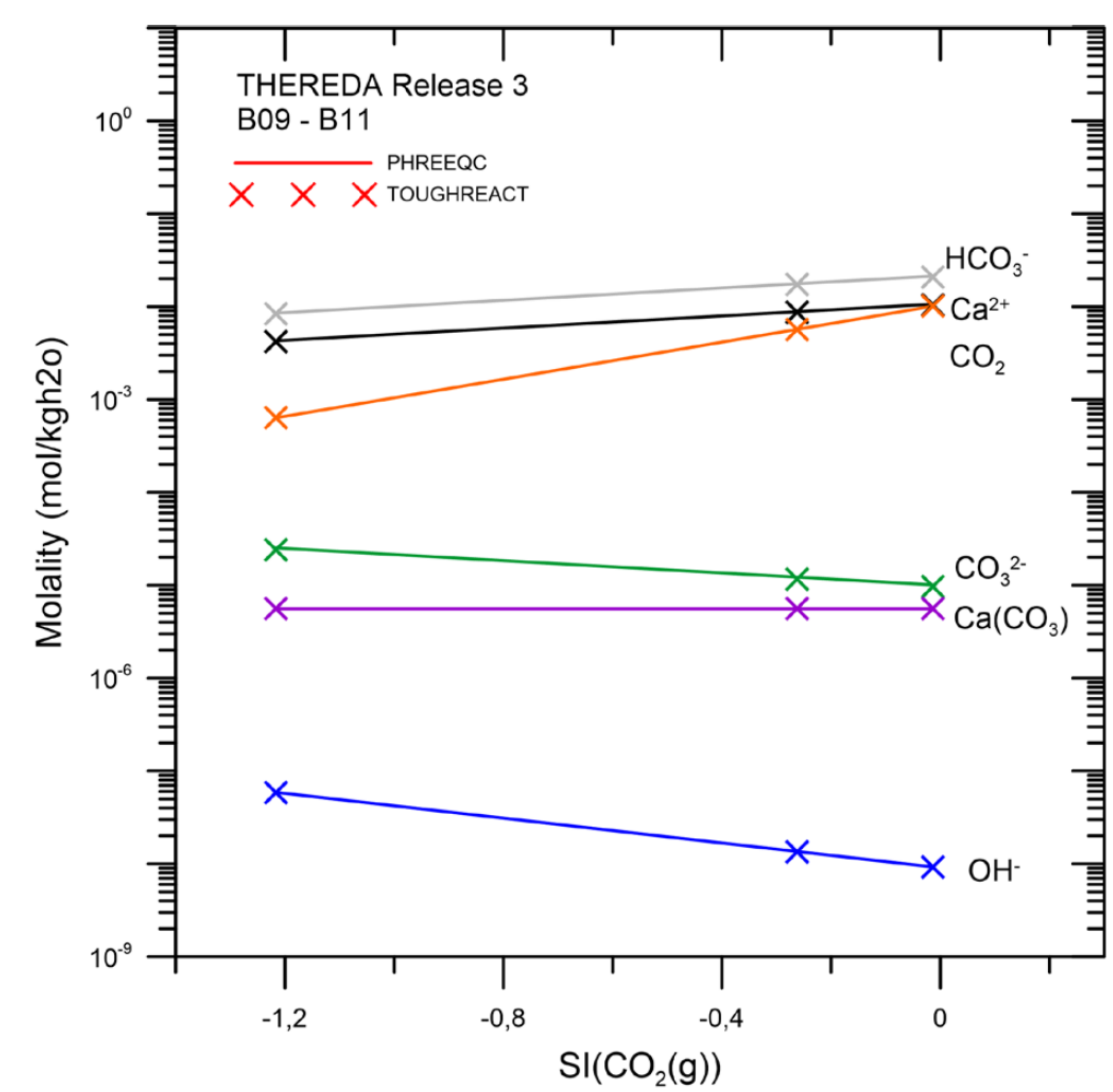

Fig. 3 Molality of aquatic species versus saturation index of $\mathrm{CO}_{2}(\mathrm{~g})$ (decadic logarithm of partial pressure) for solution in equilibrium with calcite and halite calculated by PHREEQC (lines) and TOUGHREACT (crosses)

\section{References}

[1] Xu, T. et al. (2017): „TOUGHREACT V3.32 Reference Manual, A Parallel Simulation Program for Non-Isothermal Multiphase Geochemical Reactive Transport" Lawrence Berkeley National Laboratory (LBNL), LBNL-DRAFT.

[2] K. S. Pitzer (1991): "Activity Coefficients in Electrolyte Solutions" CRC Press, ISBN o8493-5415-3

[3] H. C. Moog et al. (2015): "Disp. of Nuclear Waste in Host Rock formations featuring highsaline solutions - Implementation of a Thermodynamic Reference Database (THEREDA)" Appl. Geochem., 55, Page 72-84. http://dx.doi.org/10.1016/j.apgeochem.2014.12.016. 